\title{
Fifth International Congress of Gerontology
}

The International Association of Gerontology has selected San Francisco, California, as the site for its Fifth International Congress of Gerontology. The dates will be August 7 to 12, 1960. On the basis of the interest already shown in the Congress it is expected that between 1500 and 2000 persons, from every continent, will participate in the Congress.

The Program - The program of the Congress will be planned in four sections: The Biological Sciences; Clinical Medicine; Psychology and the Social Sciences, and Social Welfare. Each section will hold six scientific sessions for the presentation of papers. These four scientific sessions will meet simultaneously. Each section's program committee will be responsible for planning a general symposium to be attended by all Congress participants. In addition there will be two plenary sessions and at least one open public meeting. In order to allow the widest possible latitude for the scientific papers, there will be no over-all Congress theme. English will be the official language for the Congress.

Information on the selection of papers is set forth in the attached notice. Its instructions should then be followed closely.

The Congress has been granted funds which will make it possible to offer some financial assistance to those whose papers will be accepted for presentation and who will require such assistance.

Registration - It is highly desirable that as many as possible register for the Congress well in advance of the opening date. The registration fee will be $\$ 25.00$ for all who register before May 31,1960 . Thereafter the registration fee will be $\$ 30.00$. Those desiring to register in advance should so inform the President of the Congress. They will be sent the necessary forms.

Exhibits - There will be ample space immediately adjacent to the meeting rooms for exhibits. All enquiries relative to commercial or scientific exhibits should be addressed to:

324

Congresses - Kongresse - Congrès

Dr. Leo Gitman, Chairman, Committee on Exhibits, Brooklyn Home for the Aged, Howard and Dumont Avenues, Brooklyn 12, New York, USA.

General Information - All enquiries, except in regard to the submission of papers or to exhibits, should be directed to:

Louis Kuplan, President, Fifth International Congress of Gerontology, Post Office Box 2103, Sacramento 10, California, USA.

Call for Papers

The International Association of Gerontology will hold its Fifth International Congress of Gerontology in San Francisco, August 7-12, 1960. The basic purpose of the Association is to promote the discovery, development and dissemination of systematic knowledge concerning the ageing process and the ageing individual as well as social changes and adaptations brought about by ageing populations. To that end, all papers submitted should represent reports of original research in the field of systematic evaluations of operating programs. Papers which merely 
describe programs or practices should be of such quality that they would be acceptable for the program of any professional or scientific society.

Abstracts of the papers to be presented at the Fifth International Congress must not exceed 250 words in length, should be typewritten in English and double-spaced, with ample margins on all sides. No tabular material shall be included in the abstracts. Four copies of each abstract should be submitted not later than December 15, 1959 to the appropriate section of the Congress as indicated below. European authors will submit their abstracts to the appropriate sections as set forth below:

Biological Sciences

Clinical Medicine

Psychology and the Social Sciences

Social Welfare

European authors

Prof. James F. Danielli

182 West Hill

Putney

London, S.W. 15, England

Dr. J. A. Huet 1 Place d'lena Paris 16, France

Henning Frits, Director Danish National Institute of Social Research Nyhavn 38 Copenhagen K., Denmark

Henning Friis, Director Danish National Institute of Social Research Nyhavn 38 Copenhagen K., Denmark

All others

Dr. Nathan W. Shock, Chief Gerontology Branch Baltimore City Hospitals Baltimore, Maryland, USA.

Dr. Herman T. Blumenthal The Jewish Hospital 216 South Kingshighway St. Louis, Missouri, USA.

Clark Tibbitts Special Staff on Ageing Department of Health Education and Welfare Washington 25, D.C., USA.

Louis Kuplan P.O. Box 2103 Sacramento 10, California, USA.

Inquiries regarding other aspects of the Fifth International Congress should be addressed to:

Louis Kuplan, President Post Office Box 2103 Sacramento 10, California, USA. 